\title{
Study on Coupled Medium effects of Complex Slotted Charge Blasting
}

\author{
Xie Hua-gang, Wu Ling-li \\ Tongling University, Anhui Tongling 244000
}

\begin{abstract}
Based on the theory of complex slotted charge water, air coupling medium directional fracture controlled blasting analysis and simulation test of similar, draw the complex slotted charge water coupling charge directional fracture controlled blasting effect is better than that of the air coupling blasting; peak pressure than the air coupled charge under the conditions of quicker acting time, effect of higher value, longer duration; water coupling blasting conditions, unit speed peak value than air coupled charge under the conditions of higher.
\end{abstract}

\section{Introduction}

Due to the rapid development of human society, the development of space has been unable to meet the needs of social development, so in accordance with the west, nineteenth Century is a railway bridge of the century, twentieth Century is the century of high-rise buildings, and in twenty-first Century will be the development and utilization of underground space century. According to the situation of our country, urbanization process is accelerating, the western big development is ongoing, China may road and bridge, high-rise buildings and underground space development and utilization of the three go hand in hand with the situation [1]. However, with the implementation of the western development, highway, railway, mining, water conservancy and hydropower, buildings, airports and ports and other infrastructure construction projects will be more and more, the rock soil engineering construction method and means is facing unprecedented challenges, and geotechnical engineering as important Shi construction method of drilling and blasting method is facing unprecedented challenges, the growing demand for its higher and higher, especially decorative stone mining [2], tunnel excavation [3-6], civil air defense engineering [7-10], cutting slope [11-13], coal mine gas drainage [14-16] and other engineering. The amount of application of cutting seam cartridge blasting method, so we need to study it further. Analysis of the blasting research workers of blasting the application and mechanism of the composite type cutting seam cartridge of provides reliable basis. The complex slotted charge instantly in the explosion due to the interaction of PVC pipe before and after, and on different coupling medium blasting characteristics of different [17,18], making explosion energy flow distribution is getting more and more complex. Therefore, it is necessary to study it further.

\section{Composite slit charge explosion cracking mechanism}

The complex slotted cartridge blasting crack mechanism of see the compound cutting seam cartridge cracking mechanism and numerical simulation experiment. The theory in the role of specific blasting parameters derived compound cutting seam cartridge than conventional cutting seam cartridge explosion in cutting seam direction of shear force more than twice as high as the [19]. That compound cutting seam cartridge in the slit direction of the cumulative effect of more high. In this paper, the numerical simulation method of further research in 
the role of different coupling mediums, composite type cutting seam cartridge blasting effect, to better use of composite type cutting seam cartridge of the shaped charge effect, and improve the utilization rate of explosion energy.

\section{Numerical simulation test research}

Blasting damage process only in a few milliseconds even tens of microseconds completed within the corresponding many mechanical properties is difficult to get from the test; also in order to reduce the test cost and time constraints, most researchers choose numerical simulation method to the corresponding research [20-22], they in the constitutive model of rock material established a large number of studies [23], which provides a theoretical basis for the damage and fracture of rock material.

In this paper, the finite element software ANSYS10.0/LS-DYNA is used for numerical calculation. For the convenience of calculation and the calculation model is simplified as an "associate" state plane, using a quarter model, dimensions are $200 \mathrm{~mm}$ $\times 150 \mathrm{~mm} \times 5 \mathrm{~mm}$, with respect to $\mathrm{x}, \mathrm{Y}$ axis symmetry, the blasting parameters see Table 1. In the model, BURN *EOS_JWL is used to simulate the change of pressure and volume in the process of explosive explosion, and the relationship between the pressure $\mathrm{P}$ and the relative volume $\mathrm{V}$ is in the process of detonation:

$$
p=A\left(1-\frac{\omega}{R_{1} V}\right) e^{-R_{1} V}+B\left(1-\frac{\omega}{R_{2} V}\right) e^{-R_{2} V}+\frac{\omega E_{0}}{V}
$$

In the formula, $A 、 B 、 R_{1} 、 R_{2} 、 \omega_{\text {is }}$ the material constant, $E_{0}$ is the initial specific energy. Explosive density by RDX, $1.63 \mathrm{~g} / \mathrm{cm} 3, D$ is $6500 \mathrm{~m} / \mathrm{s}$ C-J, detonation velocity, pressure is $18.5 \mathrm{GPa}$. The density, elastic modulus and Poisson's ratio of PVC tube were $1.33 .1 \mathrm{MPa}, \mathrm{g} / \mathrm{cm} 3$ and 0.38 , respectively. The density of water is $1.02 \mathrm{~g} / \mathrm{cm} 3$. Air density is $1.29 \mathrm{x}$ 10-3g/cm3. KINEMATIC *MAT_PLASTIC_, which is used to model the rock, is a mixture model with the strain rate and the failure of isotropic, kinematic hardening or isotropic and kinematic hardening, and the parameters are shown in table 1 . The stress-strain relationship is as follows:

$$
\sigma_{Y}=\left[1+\left(\frac{\dot{\varepsilon}}{C}\right)^{1 / p}\right]\left(\sigma_{0}+\beta E_{P} \varepsilon_{P}^{e f f}\right)
$$

Table 1 Parameter of rock

\begin{tabular}{cccccc}
\hline $\begin{array}{c}\text { Coupl } \\
\text { ed } \\
\text { mediu } \\
\mathrm{m}\end{array}$ & explosi & $\mathrm{db} / \mathrm{m}$ & $\rho / 103 \mathrm{~kg} \cdot$ & $\sigma / \mathrm{MP}$ & $\mathrm{E} / \mathrm{M}$ \\
\hline Water & RDX & $\mathrm{m}$ & $\mathrm{m}-3$ & $\mathrm{a}$ & $\mathrm{Pa}$ \\
\hline & 16 & 1.10 & 1.60 & $\begin{array}{c}169.4 \\
5\end{array}$ \\
\hline
\end{tabular}

In the formula, $\sigma_{0}$ is the initial yield stress; $\varepsilon$ is strain rate; $C, P$ is symonds Cowper strain rate parameter; $\varepsilon_{P}^{\text {eff }}$ is equivalent plastic strain; $E_{P}=E_{\tan } E /\left(E-E_{\text {tan }}\right)$ plastic hardening modulus; $\beta$ for hardening parameter ( $\beta=0$ only with kinematic hardening, $\beta=1$ isotropic hardening); stress strain characteristics can only be given at a temperature.

\subsection{Blasting effect}

Figure 1 shows the complex slotted cartridge in the air under the condition of the coupling, the initial explosion $\mathrm{t}=2.7 \mathrm{us}$ explosion effect chart, from the chart can be seen, PVC inner layer tube in under the action of the detonation products to the outer PVC pipe direction. When the internal and external PVC pipe contact, in PVC inner layer pipe crack tip and crack opening took place. Finally in the outer PVC pipe cutting seam crack occurred at the. So a composite type of cutting seam charge air coupled directional fracture effect than water coupled directional fracture effect. It also can by comparing Figure 1 and Figure 2 has been proved. 


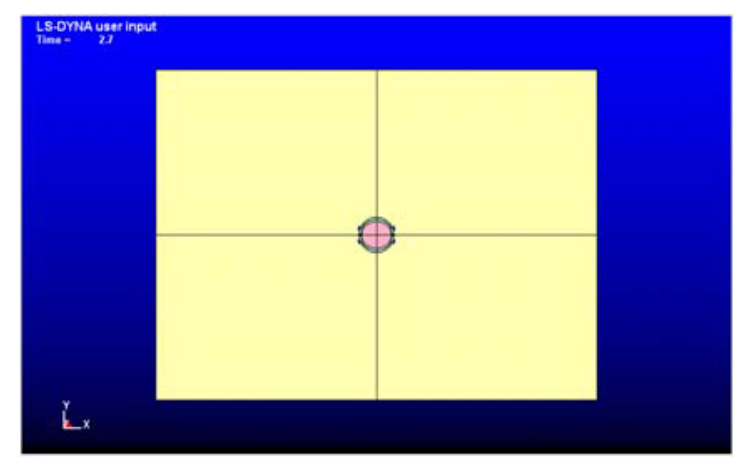

Fig.1 Blasting effect

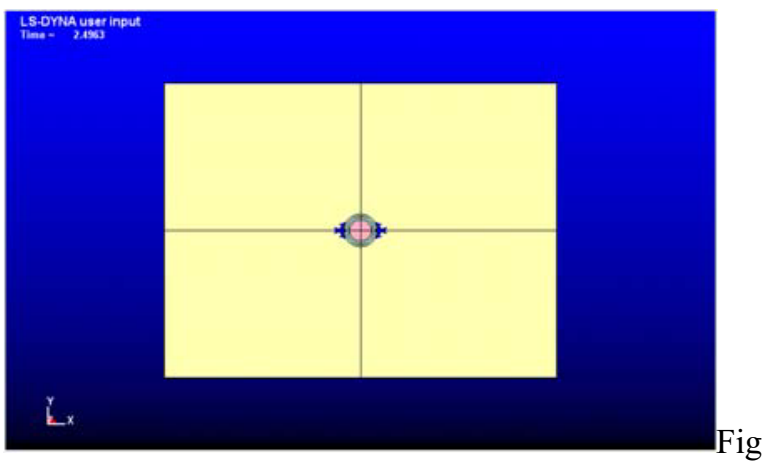

.2 Blasting effect

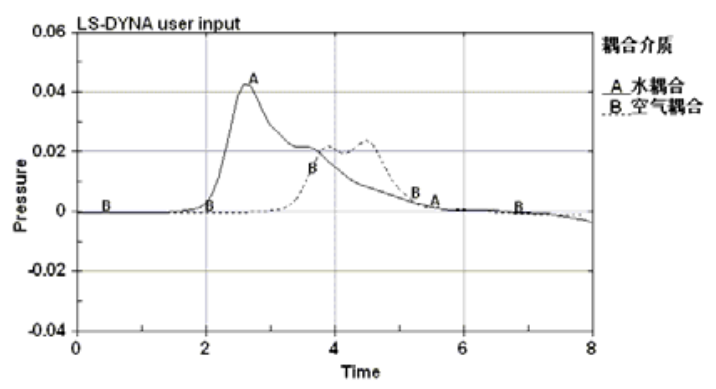

Fig.3 Two kind of coupling medium unit pressure

contrast

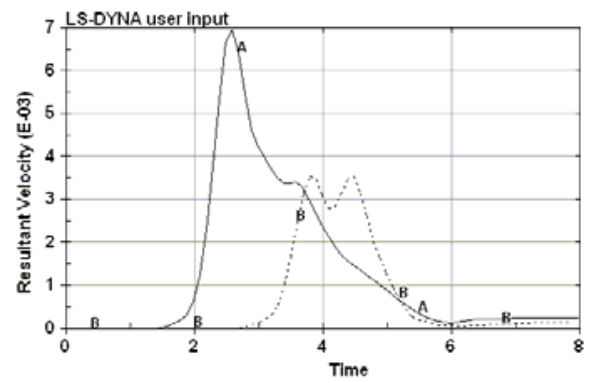

Fig.4 Two kind of coupling medium unit resultant velocity contrast

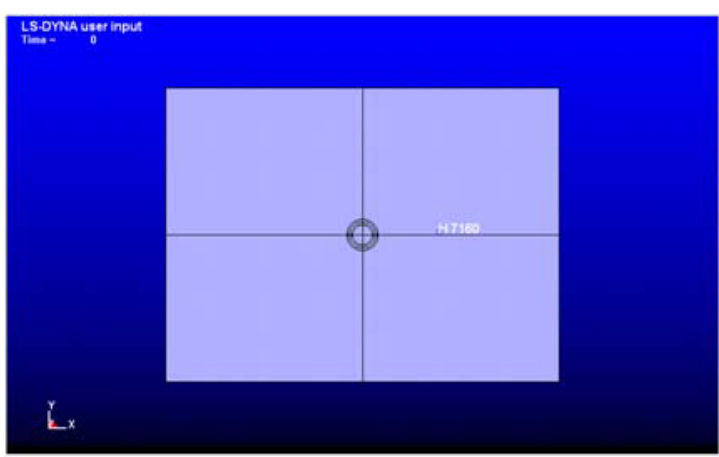

Fig.5 Unit position

\subsection{Comparison of mechanical properties of two kinds of coupling medium}

Figure 3 and Figure 4 were given compound cut under the condition of water and air coupling charge suture and cutting seam direction unit pressure and velocity contrast curve. Location of the unit is shown in figure 5. Compared with the curve A, the curve B can get the following conclusion:

(1) under the condition of water coupling, the peak value of unit pressure is 1.92 times of the air coupled condition. The explosive power of the same kind of explosive is different in the two kinds of coupling medium. Due to the water and air with different density (water density $\rho=1024.6 \mathrm{~kg} / \mathrm{m} 3$, and air density $\rho=1.226 \mathrm{~kg} / \mathrm{m} 3$, the density of water about to 835 times the air) and different compression of air is a compressible of, and the water compressibility is usually only air 30000 to 20000 . It is generally believed that is incompressible). When explosive explosion, the compressibility of the coupling medium water is very small, the ability to save energy is very low, it can be used as a good conductor, so that the blast shock wave can be transmitted to the hole wall, so the explosion pressure in water is higher than in the air.

(2)the initial pressure peak time is earlier than the air coupling. The compressibility of water is small, and the air is compressed. Therefore, when the explosion occurs, the potential energy of the coupling medium water is very small, the explosion shock wave directly acts on the wall of the blasting hole, and in the air of the coupling medium, the explosion product first compressed air medium, so that the potential energy of the air can reach a certain extent. 
(3) the duration of the pressure is 2 times of the air coupling. In the coupled medium water explosion, the pressure acting time is close to 4us; and the explosion in the air of the coupling medium, the pressure acting time is 2us.

(4) under the condition of water coupling, the peak value of unit velocity is 2 times of the air coupled condition.

\section{4 conclusions}

Based on the composite cutting simulation test comparison analysis and numerical charge theory, draws the following conclusion:

(1) The complex slotted cartridge water coupling blasting effect is better than that of air coupling blasting;

(2) water coupling blasting conditions, the peak pressure than the air coupled loading fast under the condition of drug action time, action value, lasted for a long time.

(3)water coupling blasting under the condition of unit peak velocity ratio of air coupled charge under the conditions of high.

Fund Project: the natural science research project of Anhui Education Department (KJ2013B299), the talent research foundation of Tongling University (2012tlxyrc09), the teaching research project of Tongling University (JY13035)

\section{References}

1. Gao Dazhao. Review and Prospect of geotechnical engineering $[\mathrm{M}]$. Beijing: China Communications Press, 2001

2. Xie Wen-bin, Zhou Xiang. Application Research of Incising the White Marble Material with Grooved Hole-well Blasting[J]. Blasting, 2007, 24(2): 45-48.(In Chinese)

3. The Yan army. Inclined joint development under the condition of tufa formations tunnel vault shaped control blasting technology [D]. Changsha: Central South University, 2012.

4. Mei Huihao. Underground bauxite mine advanced detection and Study on tunnel smooth blasting technology [D]. Changsha: Central South
University, 2013

5. Huang Qiang. Study on [D]. Wuhan stress of tunnel surrounding rock based on viscoelastic theory: Wuhan University of Technology, 2012

6. Yan Chun. After the earthquake are Wen Road special heights should force phenomenon and the tunnel rock explosion prevention [D]. Chengdu: Chengdu University of science and technology, 2012.

7. Zhong Guang. Research on mechanical behavior and environmental impact of construction of city tunnel by mining method [D]. Beijing: China Academy of Railway Science, 2013

8. Yang Kewen. Study on Key Technologies of urban tunnel through air defense hole [D]. Beijing: Beijing Jiaotong University, 2013

9. Wang Yafei. Experimental study and control of vibration reduction for tunnel drilling and blasting under complex environment [D]. Beijing: Beijing Jiaotong University, 2013

10. Zhao Lu-xue. Analysis on selection of TBM city track traffic engineering $[\mathrm{J}]$. Modern Tunneling Technology, 2013(02): 7-13+33. (In Chinese)

11. Zhao Ke. The stability analysis of high and steep slope of the double tunnel through the landslide section [D]. Chengdu: Southwest Jiao Tong University, 2014

12. Wang Zhiqiang. Gansu Yintao project of major engineering geological problems research [D]. Lanzhou: Lanzhou University, 2006

13. Huangdan. Shallow buried, large span tunnel of controlled blasting and the scheme of the controlled blasting of [D].[place of publication unknown]: Chongqing Jiaotong University, 2012.

14. Wang Shuang-kai. Low permeability coal seam gas extraction technology[J]. China Science and Technology Information, 2014(02): 45-46.(In Chinese)

15. Hu Jin-hong. Application of high ground stress of outburst coal seam directional pressure relief and permeability increasing technology[J]. Zhongzhou Coal, 2014(02): 58-59+62.(In Chinese)

16. Guo You-hui, Feng Zeng-chao, Liu Jian-guang, et al. Application of deep hole high pressure hydraulic cutting seam technology to increase permeability in 
coal seam with outburst danger[J]. Shanxi Coal, 2014(03): 73-75.(In Chinese)

17. Zhong Ming-shou, Long Yuan, Xie Quan-min, et al. Analysis of different borehole coupling medium on explosion seismic signal of carbonate rocks influence[J]. Chinese Journal of Rock Mechanics and Engineering, 2011(04): 702-708.(In Chinese)

18. [18] Zhong Ming-shou, Long Yuan, Li Xing-hua, et al. The wall of the hole hole of different coupling medium explosive loading and specific energy function analysis based on time[J]. Journal of Vibration and Shock, 2011(07): 116-119.(In Chinese)

19. Xie Hua-gang, Ruan Huai-ning, Wu Ling-li. Complex Ligamented Charge Holders Slitting Mechanism and Numerical Simulation Experiment[J]. Chinese Journal of High Pressure
Physics, 2012, V26(02): 205-210.(In Chinese)

20. Wang T, Yu W-1, Dong S-q, et al. Influence of the Cell Wall Thickness of Core on the Dynamic Response of Square Honeycomb Sandwich Plate Subjected to Blast Loading[J]. Advanced Materials Research, 2011, 160: 1732-1737.

21. Shao X-n, Xu Y, Wang H-b. Influence of Blasting Vibration on Roadway Loose Range[J]. Advanced Materials Research, 2011, 243: 2518-2522.

22. Tu S, Wang F, Lu Y, et al. Practice and Prospect of Fully Mechanised Mining Technology for Thin Coal Seams under Complex Conditions in China[J]. 2011

23. Lu Y, Xu K. Modelling of dynamic behaviour of concrete materials under blast loading[J]. International Journal of Solids and Structures, 2004, 41(1): 131-143. 